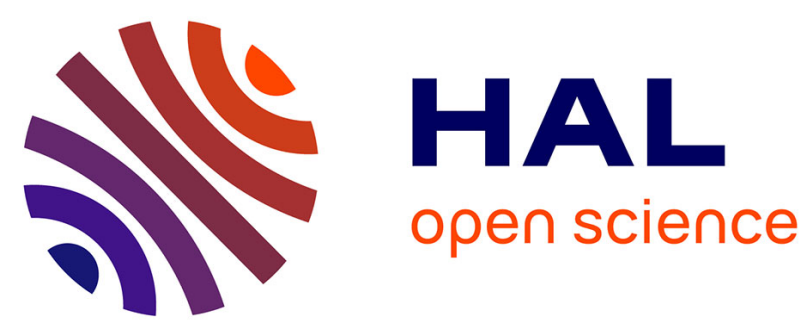

\title{
Series of charge transfer complexes obtained as crystals in a confined environment
}

\author{
Ali Sanda Bawa, Rita Meunier-Prest, Yoann Rousselin, Jean-Pierre \\ Couvercelle, Christine Stern, Bernard Malézieux, Marcel Bouvet
}

\section{To cite this version:}

Ali Sanda Bawa, Rita Meunier-Prest, Yoann Rousselin, Jean-Pierre Couvercelle, Christine Stern, et al.. Series of charge transfer complexes obtained as crystals in a confined environment. CrystEngComm, 2021, 23 (36), pp.6418-6426. 10.1039/d1ce00929j . hal-03365189

\author{
HAL Id: hal-03365189 \\ https://hal.science/hal-03365189
}

Submitted on 5 Oct 2021

HAL is a multi-disciplinary open access archive for the deposit and dissemination of scientific research documents, whether they are published or not. The documents may come from teaching and research institutions in France or abroad, or from public or private research centers.
L'archive ouverte pluridisciplinaire HAL, est destinée au dépôt et à la diffusion de documents scientifiques de niveau recherche, publiés ou non, émanant des établissements d'enseignement et de recherche français ou étrangers, des laboratoires publics ou privés. 
A. Sanda Bawa et al. CrystEngComm 2021, DOI 10.1039/d1ce00929j

\section{Graphical abstract}

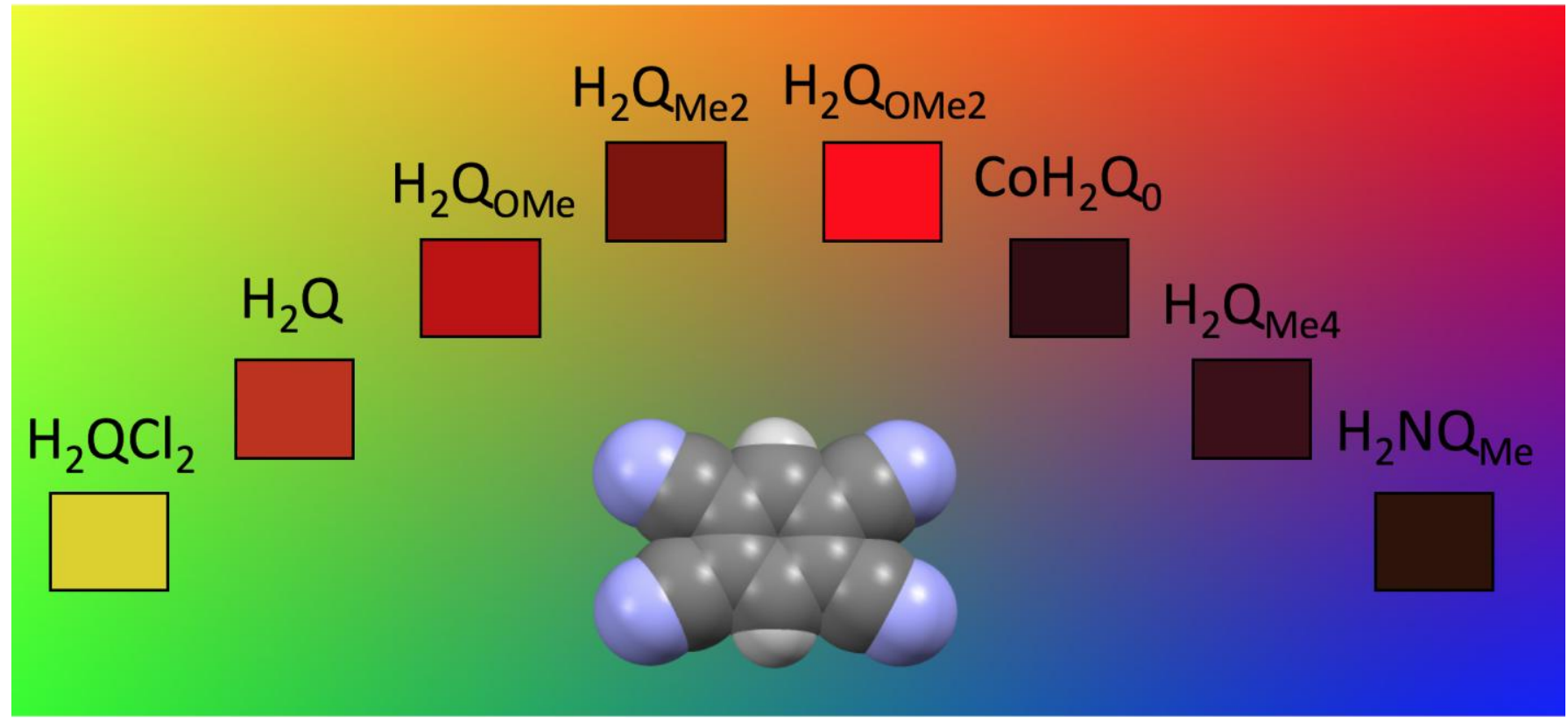




\title{
Series of charge transfer complexes obtained as crystals in a confined environment
}

\author{
Ali Sanda Bawa ${ }^{a, b}$, Rita Meunier-Prest ${ }^{a}$, Yoann Rousselin $^{a}$, Jean-Pierre Couvercelle ${ }^{a}$, Christine Stern $^{a}$, Bernard Malézieux ${ }^{c}$, \\ Marcel Bouvet ${ }^{* a}$ \\ A series of charge transfer complexes (CTCs) were successfully formed by solvent free processing techniques, using the 1,2,4,5-tetracyano benzene (TCNB) as \\ $\pi_{A}$ molecule and a series of p-dihydroquinones $\left(\mathrm{H}_{2} \mathrm{Qs}\right)$ as $\pi_{\mathrm{D}}$ counterparts. Additionally to the classical co-evaporation techniques, we obtained CTCs in less \\ than an hour, in a very simple confined environment, between two $100 \mu \mathrm{m}$ - spaced glass plates. A systematical study by Raman spectroscopy on crystals \\ highlighted the CTCs formation. Moreover, three new crystalline structures were obtained, namely TCNB- $\mathrm{H}_{2} \mathrm{Q}$ that crystallizes in columns connected to each \\ other by $\mathrm{H}$-bonds, while with the dimethoxy- $\mathrm{H}_{2} \mathrm{Q}$ s the CTC forms crystals with the stoichiometry 1:2, TCNB- $\left(\mathrm{H}_{2} \mathrm{Q}_{\mathrm{ome}}\right)_{2}$ and TCNB- $\left(\mathrm{H}_{2} \mathrm{Q}_{\mathrm{ome}}\right)_{2}$. In TCNB- $\left(\mathrm{H}_{2} \mathrm{Q}_{\mathrm{ome}}\right)_{2}$ \\ layers are formed due to intermolecular hydrogen bonds, while in TCNB- $\left(\mathrm{H}_{2} \mathrm{Q}_{\mathrm{ome}}\right)_{2}$ molecules arrange in triads, with $\pi_{\mathrm{A}^{-}} \pi_{\mathrm{D}}$ interactions. In all cases, strong \\ $\pi_{\mathrm{A}}-\pi_{\mathrm{D}}$ interactions exist with intermolecular distances lower than the van der Waals distances, which results in strong absorption bands in the visible range.
}

\section{Introduction}

Among molecular materials, when van der Waals interactions exclusively rule their building, their optical and electronic properties are directly related to the energy of the frontier molecular orbitals, the highest occupied molecular orbital, HOMO, and the lowest unoccupied molecular orbital, LUMO, of the molecular units. It is quite different when strong intermolecular interactions take place in the solid state. The control of self-organization via intermolecular interactions, among which hydrogen-bonding and donor-acceptor tandems, is of a major interest in understanding and obtaining complex systems in chemistry, biology or in materials science ${ }^{1,2}$.

Charge transfer complexes (CTCs) that combine $\pi$ donor $\left(\pi_{\mathrm{D}}\right)$ and $\pi$ acceptor $\left(\pi_{\mathrm{A}}\right)$ molecules display totally different optical and electronic properties compared to those observed for separated entities. Thus, quinhydrones, well-known charge transfer complexes between benzoquinones (BQ) and dihydroquinones $\left(\mathrm{H}_{2} \mathrm{Q}\right)$, exhibit a broad and intense band centred around $500 \mathrm{~nm}$, resulting from strong $\pi-\pi$ interactions inside the donor-acceptor stacks, associated with intermolecular distances shorter than the van der Waals distances, while both partners display a maximum absorption wavelength in ultra-violet ${ }^{3}$. Quinones and hydroquinones play a key role in many biological systems, e.g. in photosystems I and II, because of their capability to transfer electrons and protons ${ }^{4,5}$. The quantum yield of fluorescence $\left(\phi_{\mathrm{F}}\right)$ can also be highly increased in CTCs, as exemplified by the distyrylbenzene - dicyanodistyrylbenzene CTC, with $\phi_{\mathrm{F}}$ up to $60 \%$ against a few $\%$ for both partners ${ }^{6}$. These materials were considered as promising materials for organic light emitting transistors. Selfassembled microtubes of mixed CTC comprising naphthalene and 1,2,4,5-tetracyanobenzene (TCNB) doped with pyrene allowed the observation of white-light emission ${ }^{7}$. Two-photon absorption was also observed in styrylpyridine - TCNB cocrystals while it was not in the individual components ${ }^{8}$. The degree of charge transfer is related to the electron accepting and electron donating properties of both partners, which can be quantified from the energy of LUMO and HOMO of $\pi_{\mathrm{A}}$ and $\pi_{D}$ species, respectively ${ }^{9}$. The degree of charge transfer can be tuned even when one of the partner is grafted on a surface, as shown by an electrochemical study on carbon electrodes with tetrathiafulvalene - TCNQ derivatives ${ }^{10}$. In the same type of CTC, the conductivity was shown to depend on the nature of donor and acceptor partners and on the stoichiometry as well, because of the control of the electron delocalization in a range not available in one-component molecular materials ${ }^{11}$. Racemic and chiral CTCs were also studied, with 1,1-bis-2naphthol derivatives as $\pi_{D}$ species combined with BQ derivatives and TCNB as $\pi_{\mathrm{A}}$ species $^{12,13}$.

Applications of $\pi_{D}-\pi_{A}$ CTCs are mainly related to their optical and electronic properties, but $\pi_{D}-\pi_{A}$ interactions are also at the origin of sensors of volatile organic compounds, in particular for the detection of energetic species like 2,4,6-trinitrotoluene (TNT), well-known as a strong $\pi_{\mathrm{A}}$ molecule ${ }^{14}$.

Even though CTCs can be evidenced by simple grinding of $\pi_{A}$ and $\pi_{D}$ species, the preparation of single crystals suitable for $X$ ray diffraction analyses remains uneasy. They can be obtained from solutions, but the choice of the solvent-non solvent pair remains difficult and crystallization may be a long process, 
from one to several days ${ }^{12,13}$. Nice crystals were obtained more rapidly from solutions, but they were suitable only for scanning electron microscopy, electron diffraction and powder $X$-ray diffraction, but not for fully determining the crystal structure $^{7}$. To overcome the solvation energies involved in the crystallization process from solutions, co-evaporation is generally preferred. Thus, perylene $-F_{x} T C N Q(x=1,2,4) C T$ single crystals were obtained in a two-zone furnace, where the two partners were set at different temperatures, a physical transport being achieved with an argon flow ${ }^{15}$. In case of ubihydroquinone, $\mathrm{CoH}_{2} \mathrm{Q}_{0}$, we already reported the structure of its CTC with TCNB, with the formula $(\mathrm{TCNB})\left(\mathrm{CoH}_{2} \mathrm{Q}_{0}\right)_{2}$, obtained by co-evaporation in a two separated compartments sublimator, both partners being heated at two different temperatures, under primary vacuum ${ }^{16}$. In some cases, the coevaporation of both counterparts can be achieved in a unique closed primary evacuated tube, as reported for the 2:1 2methoxybenzoquinone $\left(\mathrm{BQ}_{\mathrm{OMe}}\right)-\mathrm{H}_{2} \mathrm{Q} \mathrm{CTC}^{3}$. Very recently, cocrystals of TCNB-polycyclic aromatic hydrocarbons (PAH) were obtained by growth via microspacing sublimation between two glass plates, by heating for $30 \mathrm{~min}$ at a temperature in the range $130-180^{\circ} \mathrm{C}$, depending on the $\mathrm{PAH}^{17}$. In the present work, we studied new CTCs based on TCNB as $\pi_{A}$ species and p-dihydroquinone derivatives as $\pi_{D}$ partners (Scheme 1). We report on different solvent-free methods to obtain CTC single crystals. We studied the CTCs by UV-visible, infrared electronic absorption and Raman spectroscopies. In addition, the energy of charge transfer was correlated with the redox potentials of the quinones.

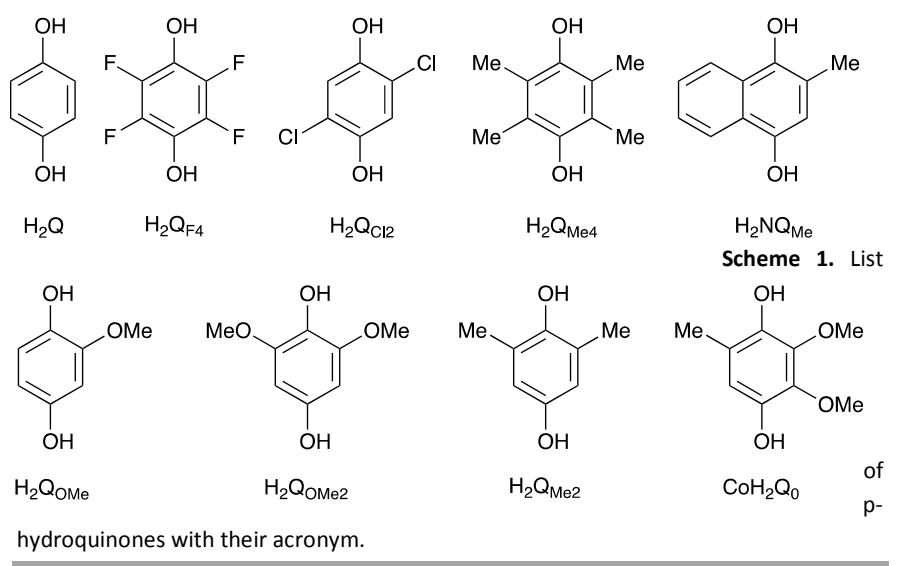

\section{Results and discussion}

\section{Crystal growth}

Three new crystal structures of TCNB - based CTCs, with $\mathrm{H}_{2} \mathrm{Q}$, $\mathrm{H}_{2} \mathrm{Q}_{\mathrm{OMe}}$ and $\mathrm{H}_{2} \mathrm{Q}_{\mathrm{OMe} 2}$ were determined. With $\mathrm{H}_{2} \mathrm{Q}_{\mathrm{OMe} 2}$, single crystals were obtained by co-evaporation of both partners in a closed primary evacuated tube, heated at a temperature of $85^{\circ} \mathrm{C}$ till dark coloured crystals appear on the cold finger (stopped after ca. 6 h). With $\mathrm{H}_{2} \mathrm{Q}$ and $\mathrm{H}_{2} \mathrm{Q}_{\mathrm{OMe}}$, single crystals were obtained by a simpler set-up, by co-evaporation in a confined environment, in between two $100 \mu \mathrm{m}$-spaced glass plates, using a metallic spacer. An equimolar mixture was finely grinded in a mortar, of which $1 \mathrm{mg}$ was deposited in between the two glass plates and heated for $30 \mathrm{~min}$, at $140^{\circ} \mathrm{C}$ for $\mathrm{H}_{2} \mathrm{Q}$ and $120^{\circ} \mathrm{C}$ for $\mathrm{H}_{2} \mathrm{Q}_{\mathrm{OMe}}$. In the present study, we also prepared a series of co-crystals with this second route, at the same temperatures for the tetrafluoro-1,4-dihydroquinone, $\mathrm{H}_{2} \mathrm{QF}_{4}$, and the 2,5-dichloro-1,4-dihydroquinone, $\mathrm{H}_{2} \mathrm{QCl}$, but at a maximal temperature of $120^{\circ} \mathrm{C}$ for the methoxy-1,4dihydroquinone, $\mathrm{H}_{2} \mathrm{Q}_{\mathrm{OMe}}$. In the case of $\mathrm{H}_{2} \mathrm{Q}_{\mathrm{OMe} 2}$, the nicest crystals were obtained without grinding the powders, but simply by mixing them; the maximal temperature was $100^{\circ} \mathrm{C}$. To avoid any degradation of molecules, each time, the slides were put on the hot plate at a temperature $20^{\circ} \mathrm{C}$ below the maximal temperature and kept at maximal temperature for 30 min. All the CTCs were characterized by infrared and Raman spectroscopies.

\section{Crystalline structures}

Structural data of the new CTCs are compiled in Table 1. TCNB$\mathrm{H}_{2} \mathrm{Q}$ crystallizes in the triclinic system (space group $\mathrm{P}-1$ ), with the stoichiometry $1: 1$, while the single crystals obtained with $\mathrm{H}_{2} \mathrm{Q}_{\mathrm{OMe}}$ and $\mathrm{H}_{2} \mathrm{Q}_{\mathrm{OMe} 2}$ correspond to the stoichiometry $1: 2$, with the formula TCNB- $\left(\mathrm{H}_{2} \mathrm{Q}_{\mathrm{OMe}}\right)_{2}$ and TCNB- $\left(\mathrm{H}_{2} \mathrm{Q}_{\mathrm{OMe} 2}\right)_{2}$, respectively. They crystallize in the triclinic (space group $\mathrm{P}-1$ ) and monoclinic (space group $\mathrm{C} 2 / \mathrm{c}$ ) systems, respectively. In TCNB- $\mathrm{H}_{2} \mathrm{Q}$, only half of the formula unit is present in the asymmetric unit, with the other half consisting of symmetry equivalent atoms (Fig. 1). Molecules arrange in columns parallel to the b-axis, having a tilt angle of ca. $28^{\circ}$ with the column axis.
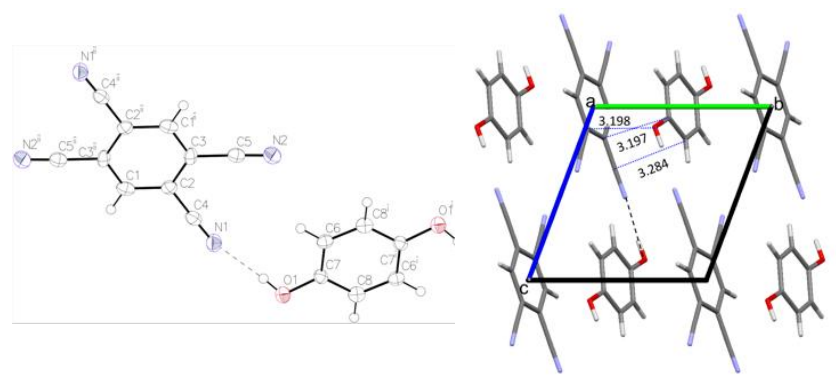

Figure 1. X-ray crystal structure of TCNB- $\mathrm{H}_{2} \mathrm{Q}$ : (left) ORTEP (50\% probability level) representation of the compound with symmetry element ('1-x,1-y,-z; ii $1-x, 2-y, 2-z)$; (right) projection of the structure along the a-axis; the shortest intermolecular distances are given (in $\AA$, dotted lines) and the H-bond shown (dashed line). 
Table 1. Structural data of charge transfer complexes.

\begin{tabular}{|c|c|c|c|}
\hline & TCNB- $\mathrm{H}_{2} \mathrm{Q}$ & TCNB- $\left(\mathrm{H}_{2} \mathrm{Q}_{\mathrm{ome}}\right)_{2}$ & TCNB- $\left(\mathrm{H}_{2} \mathrm{Q}_{\mathrm{OMe} 2}\right)_{2}$ \\
\hline $\begin{array}{c}\text { Formula } \\
F_{w}\end{array}$ & $\begin{array}{c}\mathrm{C}_{16} \mathrm{H}_{8} \mathrm{~N}_{4} \mathrm{O}_{2} \\
288.26\end{array}$ & $\begin{array}{c}\mathrm{C}_{24} \mathrm{H}_{18} \mathrm{~N}_{4} \mathrm{O}_{6} \\
458.42\end{array}$ & $\begin{array}{c}\mathrm{C}_{13} \mathrm{H}_{11} \mathrm{~N}_{2} \mathrm{O}_{2} \\
259.24\end{array}$ \\
\hline Crystal colour & light orange & $\begin{array}{l}\text { Clear light } \\
\text { orange }\end{array}$ & $\begin{array}{l}\text { metallic dark } \\
\text { black }\end{array}$ \\
\hline shape & plate & Plate & prism \\
\hline and size $(\mathrm{mm})$ & $\begin{array}{c}0.16 \times 0.09 \times \\
0.06\end{array}$ & $\begin{array}{c}0.56 \times 0.41 \times \\
0.09\end{array}$ & $\begin{array}{c}0.17 \times 0.12 \times \\
0.12\end{array}$ \\
\hline Space group & $\begin{array}{l}\text { Triclinic } \\
\text { P-1 }\end{array}$ & $\begin{array}{l}\text { Triclinic } \\
\text { P-1 }\end{array}$ & $\begin{array}{c}\text { Monoclinic } \\
\text { C2/c }\end{array}$ \\
\hline a $(\AA ̊)$ & $6.3120(4)$ & 7.0977(3) & 18.7810(12) \\
\hline b (Å) & $7.4057(5)$ & $7.7054(4)$ & $7.6668(5)$ \\
\hline$c(\AA ̊)$ & $8.1661(5)$ & $10.1834(5)$ & $17.9141(8)$ \\
\hline$\alpha\left(^{\circ}\right)$ & $108.309(5)$ & $79.616(2)$ & 90 \\
\hline$\beta\left({ }^{\circ}\right)$ & 109.791(4) & $85.590(3)$ & $112.728(3)$ \\
\hline$\gamma\left({ }^{\circ}\right)$ & $92.810(5)$ & $70.030(3)$ & 90 \\
\hline$V\left(\AA^{3}\right)$ & $335.79(4)$ & $514.64(4)$ & $2379.2(2)$ \\
\hline Z & 1 & 1 & 4 \\
\hline $\mathrm{D}_{\mathrm{c}}\left(\mathrm{g} \mathrm{cm}^{-3}\right)$ & 1.425 & 1.479 & 1.447 \\
\hline $\mathrm{T}(\mathrm{K})$ & 100 & 100 & 200 \\
\hline$\theta\left(^{\circ}\right)$ & $6.153-66.706$ & 4.416-66.792 & $2.35-27.46$ \\
\hline $\begin{array}{c}\text { Total nb } \\
\text { reflections }\end{array}$ & 2906 & 11444 & 4818 \\
\hline $\begin{array}{c}\mathrm{Nb} \text { independent } \\
\text { data }\end{array}$ & 1163 & 1824 & 2698 \\
\hline $\begin{array}{l}\mathrm{Nb} \text { data used for } \\
\text { refinement }{ }^{\mathrm{a}}\end{array}$ & 927 & 1358 & 2129 \\
\hline Merging R & 0.0615 & 0.0994 & 0.0540 \\
\hline$R w^{* b}$ & 0.1915 & 0.1137 & 0.1019 \\
\hline
\end{tabular}

${ }^{\mathrm{a}}(\mathrm{Fo})^{2}>1.5 \sigma(\mathrm{Fo})^{2} ;{ }^{\mathrm{b}} \mathrm{Rw}^{*}=\left[\Sigma \mathrm{w}(|| \mathrm{Fo}|-| \mathrm{Fc}||)^{2} / \Sigma \mathrm{wFo}^{2}\right]^{1 / 2}$

The angle between mean planes defined by the aromatic rings is $3.5(2)^{\circ}$. The acceptor-donor distance between centroids is 3.7028(3) Å. However, the shortest distances from centroids to mean planes are 3.262(5) and 3.269(4) $\AA$, as defined from the projection along the normal to these planes, indicating strong $\pi_{\mathrm{A}}-\pi_{\mathrm{D}}$ interactions. Three intermolecular distances shorter than the sum of the van der Waals radii can be depicted,

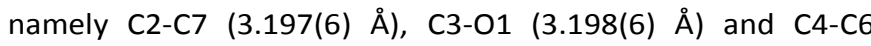
(3.284(6) Å) (Table 2). The columns are connected to each other through $\mathrm{H}$-bonds that involve an $\mathrm{N}$-atom, with a distance O1...N1 of $2.854(5) \AA$ and an angle $\mathrm{O} 1-\mathrm{H} 1$...N1 of $176.2(3)^{\circ}$. These $\mathrm{H}$-bonds, added to the strong $\pi_{\mathrm{A}}-\pi_{\mathrm{D}}$ interactions define layers. The shortest distance between layers lie between 01 and $\mathrm{H} 1$ from a neighbouring molecule (distance $=2.292(3) \AA$ ). The distance $\mathrm{C} 1-\mathrm{O} 1=3.225(5) \AA$, with an angle $\mathrm{C} 1-\mathrm{H} 1 \ldots \mathrm{O} 1=$ $167.0(3)^{\circ}$, is indicative of weak interlayer interactions.

Contrarily to TCNB- $\mathrm{H}_{2} \mathrm{Q}$, TCNB- $\left(\mathrm{H}_{2} \mathrm{Q}_{\mathrm{OMe}}\right)_{2}$ forms triads in which the two hydroquinone molecules interact with the TCNB molecule (Fig. 2). We already reported such triads with the coenzyme $\mathrm{CoH}_{2} \mathrm{Q}_{0}$, obtained by co-evaporation with TCNB in a two-separated-compartments home-made sublimator, heated at two different temperatures, under primary vacuum ${ }^{16}$. In TCNB- $\left(\mathrm{H}_{2} \mathrm{Q}_{\mathrm{OMe}}\right)_{2}$, the A-D distance between centroids is $3.4994(2) \AA$, with an angle of $6.01(8)^{\circ}$ between the mean planes, while from centroids to mean planes the A-D distances are 3.163(1) and 3.292(1) $\AA$ indicative of strong $\pi_{A}-\pi_{D}$ interactions. Columns can be considered as formed by triads corresponding to each other by the inversion centre, but with weak intermolecular interactions between neighbouring hydroquinone molecules. The distance between their mean planes is 3.5(2) $\AA$, i.e. highly longer than between acceptor and donor molecules inside a triad (3.4994(2) $\AA$ ). H-bonds involve two of the $\mathrm{N}$ atoms of TCNB, but of very weak energy, as depicted from the distance O1-H1...N1 (3.224(2) $\AA$ ) and the angle $\mathrm{O} 1-\mathrm{H} 1$...N1 $\left(169.1(1)^{\circ}\right)$.

However, $\mathrm{H}$-bonds exist between $\mathrm{H}_{2} \mathrm{Q}_{\mathrm{OMe} 2}$ molecules belonging to neighbouring triads and ensure the cohesion of molecules in planes: distance $03-\mathrm{H} 3 \ldots \mathrm{O} 2=2.685(2) \AA$ (angle $\left.=113.5(1)^{\circ}\right)$ and distance $\mathrm{O} 3-\mathrm{H} 3 \ldots \mathrm{O} 1=2.943(2) \AA$ (angle $\left.=155.3(1)^{\circ}\right)$; O 1 and $\mathrm{O} 3$ belong to hydroxyl groups while $\mathrm{O} 2$ belongs to a methoxy group. The interactions between planes are ensured by the strong $\pi_{A}-\pi_{D}$ interactions. In this structure, not least than eight intermolecular distances are shorter than the sum of the van der Waals radii (Table 2). The shortest $\mathrm{C}-\mathrm{O}$ distances are $\mathrm{C} 12-\mathrm{O} 3(3.098(2) \AA)$ and $\mathrm{C} 10-\mathrm{O} 4(3.166(3) \AA)$ and the shortest C-C distances are C10-C3 (3.238(3) $\AA$ ) and C11-C4 (3.281(3) A). This organization in triads was already reported for the TCNB- $\left(\mathrm{COH}_{2} \mathrm{Q}_{0}\right)_{2}$, but with a different 3D organization ${ }^{16}$. Thus, $\mathrm{H}$-bonds between $\mathrm{CoH}_{2} \mathrm{Q}_{0}$ units provide a zig zag arrangement, the chains being connected to each other through $\pi_{A}-\pi_{D}$ interactions, defining sheets. The chains of one layer make an angle of $82^{\circ}$ with chains from neighbouring layers, in such a way that the molecules do not arrange in infinite columns.

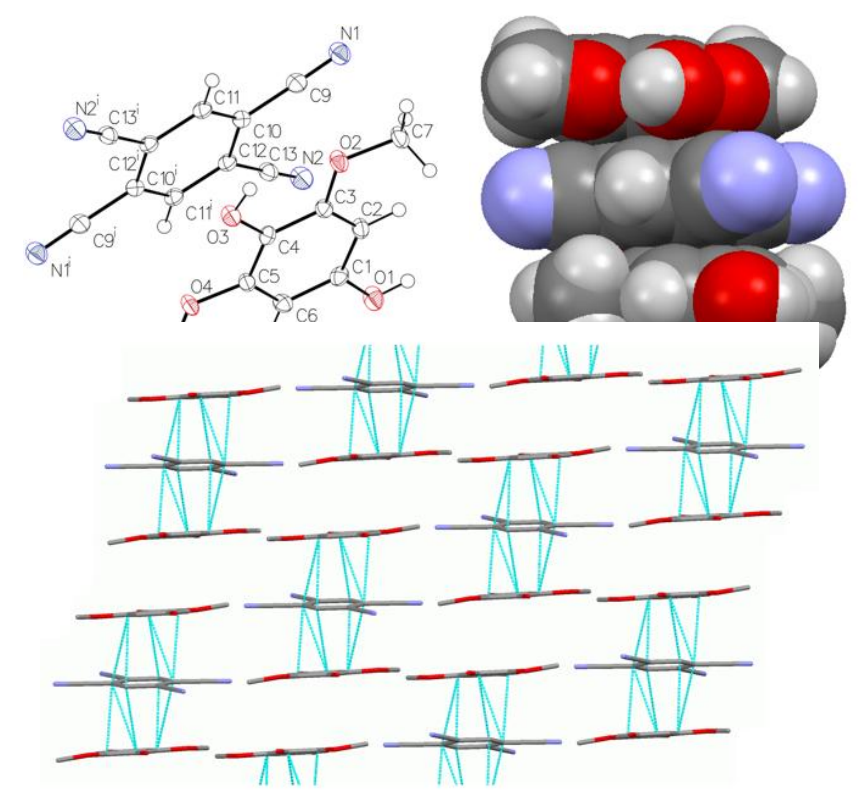

Figure 2. X-ray crystal structure of TCNB- $\left(\mathrm{H}_{2} \mathrm{Q}_{\mathrm{OMe}}\right)_{2}$ : (top left) ORTEP view (50\% probability level) with symmetry element ( $3 / 2-x, 1 / 2-y, 1-z)$, (top right) view of an ADA triad (100\% van der Waals radii) and (bottom) view of the structure showing the triads aligned in column parallel to the b-axis; the shortest intermolecular distances are shown (dotted line). 
TCNB- $\left(\mathrm{H}_{2} \mathrm{Q}_{\mathrm{OMe}}\right)_{2}$ crystallizes also with two hydroquinone molecules in $\pi-\pi$ interaction with one TCNB molecule (Fig. 3 ). The A-D distance between centroids is $4.727(2) \AA$, which is highly longer than in the two other new structures presented here, with an angle of $2.4(5)^{\circ}$ between the mean planes, while from centroids to mean planes the A-D distances are 3.198(8) and $3.280(11) \AA$. It results that, in the triads, molecules are highly shifted, the carbon atoms of nitrile units being about above the centroid of the hydroquinone ring, indicative of rather small $\pi_{A}-\pi_{D}$ interactions. Only three intermolecular distances between $A$ and $D$ molecules are shorter than the sum
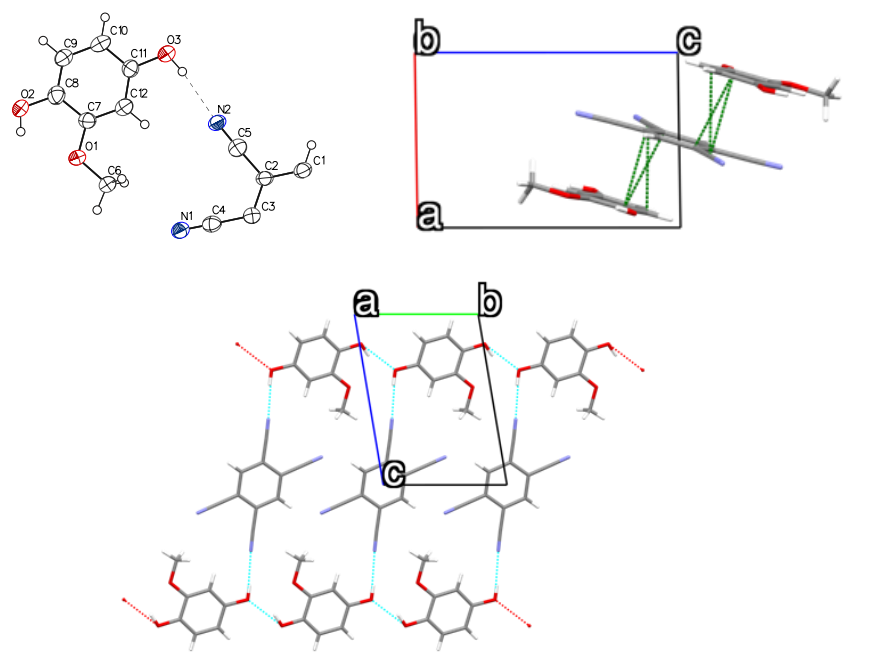

Figure 3. X-ray crystal structure of TCNB- $\left(\mathrm{H}_{2} \mathrm{Q}_{\mathrm{OMe}}\right)_{2}$ : (top left) ORTEP view (50\% probability level) without symmetry element; (top right) view of a triad obtained by projection along the b-axis; (bottom) view of a layer obtained by projection along the aaxis, the intermolecular $\mathrm{H}$-bonds are shown (dotted line). of van der Waals radii, namely C3-C8, 3.334 (8) Å, C4-C9, 3.391(8) $\AA$ and $\mathrm{C} 4-\mathrm{C} 8,3.399$ (8) $\AA$. H-bonds involve two of the $\mathrm{N}$ atoms of TCNB, with a distance O3-H3...N2 of 3.050(6) $\AA$ and an angle O3-H3...N2 of $169.1(3)^{\circ}$, indicative of a rather strong $\mathrm{H}$-bond. Another $\mathrm{H}$-bond lies between two neighbouring $\mathrm{H}_{2} \mathrm{Q}_{\mathrm{OMe}}$ molecules. These $\mathrm{H}$-bonds generate layers visible by projection along the a-axis (Fig. 3). Powder XRD (PXRD) analysis carried out in a capillary confirmed that all the batch obtained by heating $20 \mathrm{mg}$ of TCNB and $\mathrm{H}_{2} \mathrm{Q}_{\mathrm{OMe}}$ in a 1:2 molar ratio, in a confined environment, with a $500 \mu \mathrm{m}$ spacer, corresponds only to the crystalline phase described in this work for TCNB- $\left(\mathrm{H}_{2} \mathrm{Q}_{\mathrm{OMe}}\right)_{2}$ (Fig. 4), for which PXRD was simulated at 100 and $298 \mathrm{~K}$ (Fig. S1). In the case of TCNB- $\mathrm{H}_{2} \mathrm{Q}$, the PXRD analysis indicated the presence of two crystalline phases, the one reported here and another one reported in literature ${ }^{18}$, additional peaks corresponding to the presence of a small amount of TCNB.

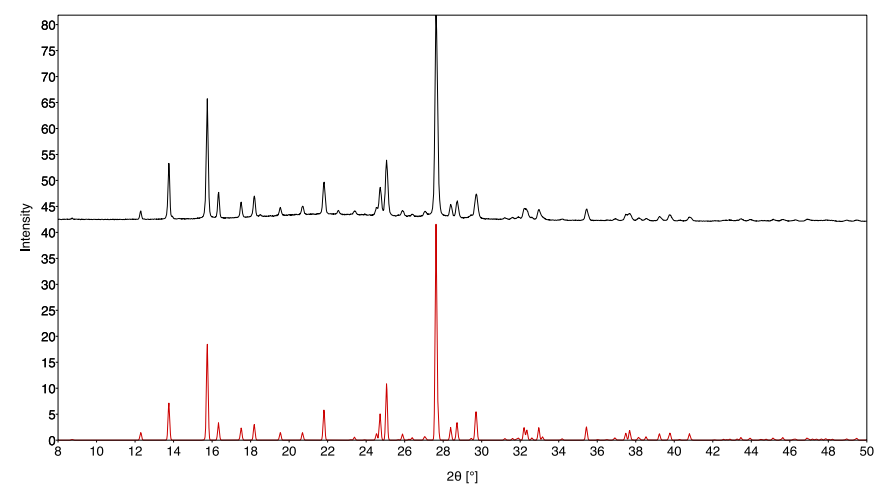

Figure 4. PXRD pattern of a batch of TCNB- $\left(\mathrm{H}_{2} \mathrm{Q}_{\mathrm{ome}}\right)_{2}$ (top) compared to the simulated pattern from a single crystal (bottom), both at $298 \mathrm{~K}$.

Table 2. Selected geometrical characteristics of charge transfer complexes.

\begin{tabular}{|c|c|c|c|}
\hline & TCNB- $\mathrm{H}_{2} \mathrm{Q}$ & TCNB- $\left(\mathrm{H}_{2} \mathrm{Q}_{\mathrm{ome}}\right)_{2}$ & TCNB- $\left(\mathrm{H}_{2} \mathrm{Q}_{\text {oмe2 }}\right)_{2}$ \\
\hline $\begin{array}{c}\text { A-D distance, from centroid to } \\
\text { mean plane }(\AA)\end{array}$ & $3.262(5) ; 3.269(4)$ & $3.198(8) ; 3.280(11)$ & $3.163(1) ; 3.292(1)$ \\
\hline $\begin{array}{c}\text { A-D distance between } \\
\text { centroids }(\AA \AA)\end{array}$ & $3.7028(3)$ & $4.727(2)$ & $3.4994(2)$ \\
\hline Angle between mean planes $\left({ }^{\circ}\right)$ & $3.5(2)$ & $2.4(5)$ & $6.01(8)$ \\
\hline $\begin{array}{l}\text { Tilt of } A \text { and } D \text { with column } \\
\text { axis }\left(\left(^{\circ}\right)^{a}\right.\end{array}$ & $28.03(14) ; 28.26(15)$ & $46.07(18) ; 47.43(13)$ & $19.83(7) ; 25.31(5)^{b}$ \\
\hline $\begin{array}{c}\text { H-bonds: dO-N }(\AA ̊) \\
\text { angle } \mathrm{OHN}\left({ }^{\circ}\right)\end{array}$ & $\begin{array}{c}2.854(5) ; \\
176.2(3)\end{array}$ & $\begin{array}{l}3.050(6) \\
169.1(3)\end{array}$ & $\begin{array}{c}3.224(2) ; \\
169.1(1)\end{array}$ \\
\hline Shortest intermolecular & C2-C7 3.197(6) & C3-C8 3.334 & C12-O3 3.098(2) \\
\hline \multirow[t]{7}{*}{ distances $(\AA ̊)$} & C3-01 3.198(6) & C4-C9 3.391 & C10-04 3.166(3) \\
\hline & C4-C6 3.284(6) & C4-C8 3.399 & C11-O3 3.173(3) \\
\hline & & & C10-C3 3.238(3) \\
\hline & & & C11-C4 3.260(3) \\
\hline & & & C11-C5 3.281(3) \\
\hline & & & C10-C4 3.353(3) \\
\hline & & & C10-C5 3.387(3) \\
\hline CN bonds (Å) & $1.143(6) ; 1.145(6)$ & & $1.144(3) ; 1.145(3)$ \\
\hline
\end{tabular}

${ }^{a}$ angle between the centroid-centroid segment and the normal to the A plane (or D plane); ${ }^{b}$ angles of A and D with the triad axis 


\section{A. Sanda Bawa et al. CrystEngComm 2021, DOI 10.1039/d1ce00929j}

\section{Calorimetric studies}

TCNB- $\left(\mathrm{H}_{2} \mathrm{Q}_{\mathrm{OMe}}\right)_{2}$ was studied by thermogravimetric analysis (TGA). The decomposition process occurs into two steps. TCNB- $\left(\mathrm{H}_{2} \mathrm{Q}_{\mathrm{OMe}}\right)_{2}$ starts to decompose as $\mathrm{H}_{2} \mathrm{Q}_{\mathrm{OMe}}$, exactly $180.2^{\circ} \mathrm{C}$ for the CTC against $179.6^{\circ} \mathrm{C}$ for $\mathrm{H}_{2} \mathrm{Q}_{\mathrm{OMe}}$ for the ONSETs, and finishes highly before TCNB, $274.3^{\circ} \mathrm{C}$ against $312.4^{\circ} \mathrm{C}$ for the ENDSETs (Fig. 5). It means that the alternation of $\mathrm{H}_{2} \mathrm{Q}_{\mathrm{OMe}}$ and TCNB molecules in columns makes the TCNB molecules less stable than when they are in TCNB crystals. It also indicates that recrystallization process of TCNB does not occur after the $\mathrm{H}_{2} \mathrm{Q}_{\mathrm{OMe}}$ decomposition. The weight loss associated to the first step, $68 \%$, is slightly higher than the mass contain of $\mathrm{H}_{2} \mathrm{Q}_{\mathrm{OMe}}$ $(60 \%)$ in the CTC. Detailed TGA data are given in Table S1.

In the TGA traces of TCNB- $\mathrm{H}_{2} \mathrm{Q}$ CTC and co-grinded compounds, decomposition occurs in two steps. For both samples, the first finishes at ca. $38 \%$ of the initial mass, which is equal to the mass fraction of $\mathrm{H}_{2} \mathrm{Q}$. TCNB- $\mathrm{H}_{2} \mathrm{Q}$ CTC starts to decompose before $\mathrm{H}_{2} \mathrm{Q}$, $181.0^{\circ} \mathrm{C}$ against $186.0^{\circ} \mathrm{C}$ for the ONSETs, and finishes slightly before TCNB, $292.3^{\circ} \mathrm{C}$ against $312.4^{\circ} \mathrm{C}$ (Fig. 6). On the contrary, the TGA of co-grinded materials at the $1: 1$ stoichiometry shows that decomposition starts approximately as the grinded $\mathrm{H}_{2} \mathrm{Q}, 182.2^{\circ} \mathrm{C}$ against $183.2^{\circ} \mathrm{C}$ for ONSETs, and finishes as grinded TCNB, $300.1^{\circ} \mathrm{C}$ against $300.5^{\circ} \mathrm{C}$ (Fig. S2). It indicates that there is no recrystallisation during the heating processes, nor of TCNB after decomposition of $\mathrm{H}_{2} \mathrm{Q}$, nor of the grinded mixture into CTC, as reported for the sulfamethazine - salicylic acid couple ${ }^{19}$. However it is not a rule, and co-crystals can be formed during heating of mixtures ${ }^{20}$. It is worth mentioning that grinded individual materials are slightly less stable than crystalline compounds (Fig. S3). Thus, grinded TCNB decomposes at $260.4^{\circ} \mathrm{C}$ against $271.7^{\circ} \mathrm{C}$ for crystals of commercial TCNT (ONSETs values), while decomposition finishes also earlier, $300.5^{\circ} \mathrm{C}$ against $312.6^{\circ} \mathrm{C}$, respectively. This difference is smaller for $\mathrm{H}_{2} \mathrm{Q}$, with ONSET values of $183.2^{\circ} \mathrm{C}$ and $186.0^{\circ} \mathrm{C}$ for commercial crystals and grinded compound, respectively, and final decomposition temperatures of $214.9^{\circ} \mathrm{C}$ and $222.3^{\circ} \mathrm{C}$

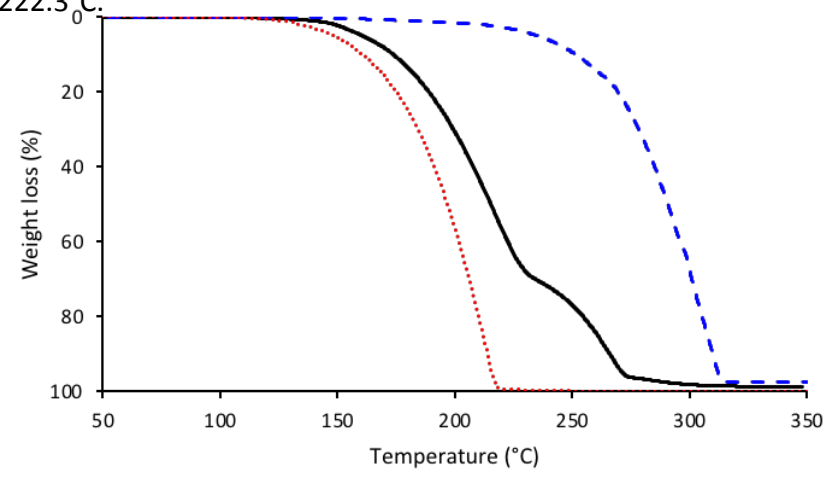

Figure 5. TGA trace of the TCNB- $\left(\mathrm{H}_{2} \mathrm{Q}_{\mathrm{OMe}}\right)_{2} \mathrm{CTC}$ (black line) compared to these of

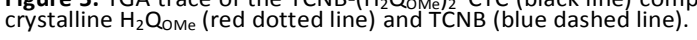

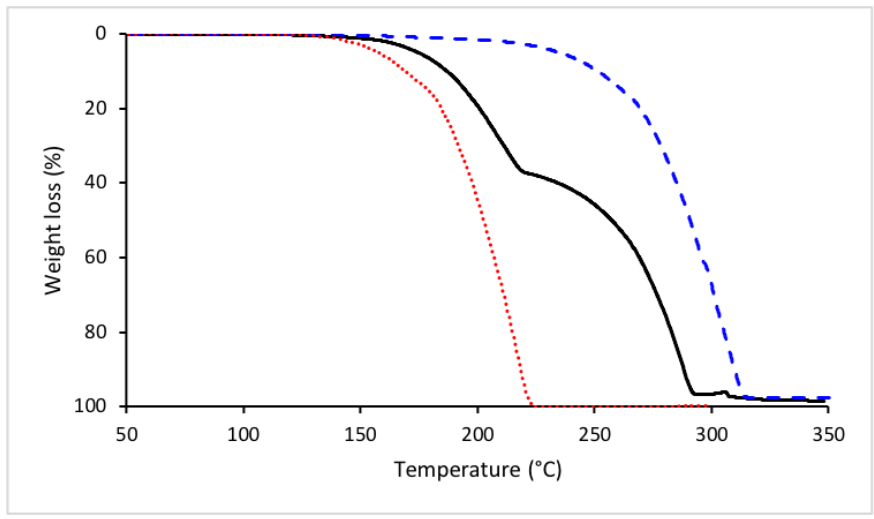

Figure 6. TGA trace of the TCNB- $\mathrm{H}_{2} \mathrm{Q}$ CTC (black line) compared to these of crystalline $\mathrm{H}_{2} \mathrm{Q}$ (red dotted line) and TCNB (blue dashed line).

\section{Infrared and Raman spectroscopy}

Infrared spectra were registered by grinding crystals obtained by co-evaporation between glass slides of the two partners. IR spectra of CTCs correspond mainly as a superimposition of spectra of both partners except for the $\mathrm{OH}$ and $\mathrm{C} \equiv \mathrm{N}$ vibrations. TCNB exhibits one C-N vibration at $2247 \mathrm{~cm}^{-1}$, whereas CTCs exhibit two $\mathrm{C}-\mathrm{N}$ vibrations, separated by up to $21 \mathrm{~cm}^{-1}$ in the case of $\mathrm{H}_{2} \mathrm{Q}$ (Fig. 7). This is in accordance with the existence of $\mathrm{H}$-bonds that involve only two of the four nitrile moieties, as shown in its crystalline structure (Fig. 1).

The two apparently degenerate modes, namely $b_{2 u}$ and $b_{3 u}$, in the $D_{2 h}$ space group of TCNB become discriminated in the $C_{2 h}$ space group of a TCNB molecules where two cyano groups in para positions are different from the two others ${ }^{16,21}$. Both vibrations are $b_{u}$ modes, but correspond to elongations towards the $\mathrm{H}$-bonds direction and along the direction of cyano groups not involved in $\mathrm{H}$-bonds, respectively (Fig. 8). This difference is $18 \mathrm{~cm}^{-1}$ with $\mathrm{H}_{2} \mathrm{Q}_{\mathrm{F} 4}$ and $9 \mathrm{~cm}^{-1}$ in the case of

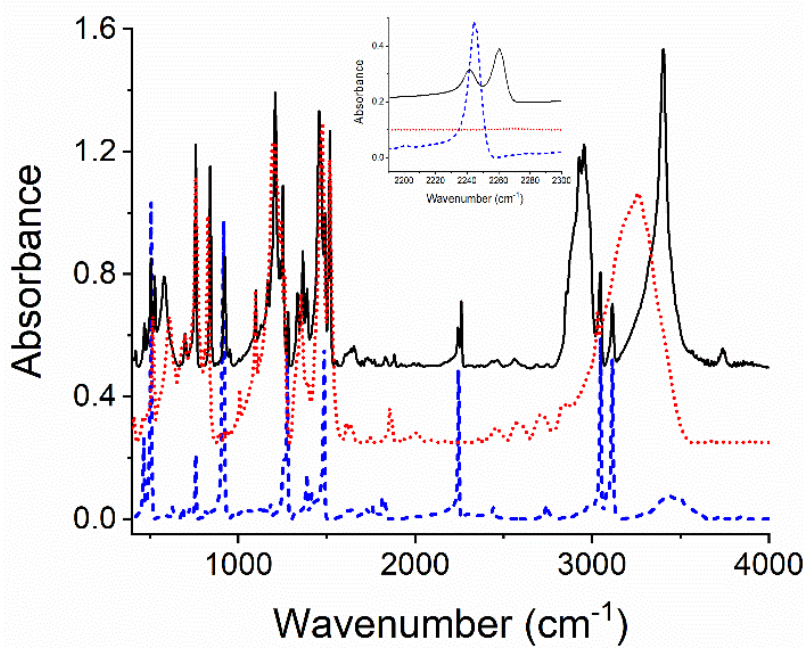


$\mathrm{H}_{2} \mathrm{Q}_{\mathrm{OMe}}$ (Fig. S4).

Figure 7. Infrared spectra of TCNB (blue dashed line), $\mathrm{H}_{2} \mathrm{Q}$ (red dotted line) and TCNB$\mathrm{H}_{2} \mathrm{Q}$ CTC (black line). Inset: zoom of the nitrile vibration region.

With $\mathrm{H}_{2} \mathrm{Q}_{\mathrm{Cl} 2}$, only one vibration is visible, but the full width at half maximum (FWHM) value increased from ca. $75 \mathrm{~cm}^{-1}$ for TCNB to $100 \mathrm{~cm}^{-1}$ for the CTC (Fig. S5). Additionally, the $\mathrm{OH}$ vibrations are also highly modified in the CTCs. In TCNB- $\mathrm{H}_{2} \mathrm{Q}$, the $\mathrm{OH}$ vibration lays at $3402 \mathrm{~cm}^{-1}$, against $3260 \mathrm{~cm}^{-1}$ for pure $\mathrm{H}_{2} \mathrm{Q}$. Moreover, this band is very thin in the complex, the FWHM value is $60 \mathrm{~cm}^{-1}$, vs. $330 \mathrm{~cm}^{-1}$ for pure $\mathrm{H}_{2} \mathrm{Q}$, indicating that all the $\mathrm{H}$-bonds have the same strength in the СTC, in contrast with what occurs in $\mathrm{H}_{2} \mathrm{Q}$, in which water molecules can be involved.

In contrast with IR, Raman spectrum of TCNB shows two peaks for nitrile vibrations, at 2239 and $2249 \mathrm{~cm}^{-1}$, attributed to $\mathrm{ag}_{\mathrm{g}}$ and $\mathrm{a}_{1 \mathrm{~g}}$ modes. These modes lead to two $\mathrm{a}_{\mathrm{g}}$ modes in the $\mathrm{C}_{2 \mathrm{~h}}$ symmetry (Fig. 8). Thus, Raman spectra of CTCs exhibit two bands whose positions depend on the species, with no shift for TCNB- $\mathrm{H}_{2} \mathrm{Q}_{\mathrm{F} 4}$ (Fig. S6, S7) compared to pristine TCNB, but at 2243 and $2260 \mathrm{~cm}^{-1}$ for TCNB- $\mathrm{H}_{2} \mathrm{Q}_{\mathrm{OMe} 2}$ (Fig. S8,S9), 2248 and $2256 \mathrm{~cm}^{-1}$ for TCNB- $\mathrm{H}_{2} \mathrm{Q}_{\mathrm{Cl} 2}$ (Fig. S10, S11), and at 2236 and $2259 \mathrm{~cm}^{-1}$ for TCNB-H 2 Q (Fig. 9). However, Raman spectra of CTCs exhibit two or three peaks, an additional peak being present in the case of $\mathrm{H}_{2} \mathrm{Q}_{\text {OMe }}\left(2239,2249\right.$ and $2260 \mathrm{~cm}^{-1}$ ) (Fig. S12, S13), showing that the local symmetry can be lower than that deduced from X-ray studies, because of the existence of strong $\pi-\pi$ interactions.

Even though most of the vibrations of both partners remain visible in the CTCs spectra, these are not a simple addition of the acceptor and donor spectra, the relative intensity being very different. Thus, in TCNB- $\mathrm{H}_{2} \mathrm{Q}$, between 1500 and $1600 \mathrm{~cm}$ 1 , the two more intense bands, at 1540 and $1598 \mathrm{~cm}^{-1}$ were very small in TCNB. Similarly, two strong bands at 722 and 730 $\mathrm{cm}^{-1}$ appear in the CTC against only one small band in TCNB, at $723 \mathrm{~cm}^{-1}$ and no vibration in $\mathrm{H}_{2} \mathrm{Q}$ (Fig. S14). Contrarily, the most intense band of $\mathrm{H}_{2} \mathrm{Q}$, at $854 \mathrm{~cm}^{-1}$, is medium in the CTC and a very thin band at $1168 \mathrm{~cm}^{-1}$ becomes strong in the CTC, at $1162 \mathrm{~cm}^{-1}$. In addition, a new strong band appears at 1227 $\mathrm{cm}^{-1}$, which was absent in both partners. This analysis confirms the existence of strong intermolecular interactions between both partners. Such an analysis is also true for the other CTCs.
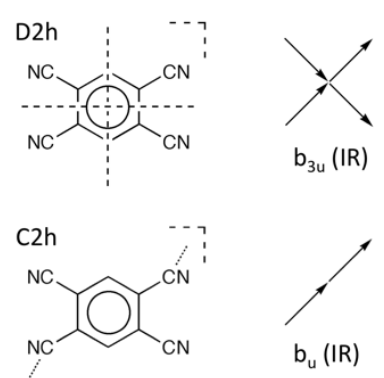

$b_{3 u}(I R)$

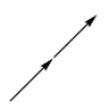

$b_{u}(I R)$

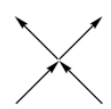

$\mathrm{b}_{2 \mathrm{u}}(\mathrm{IR})$

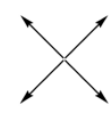

$a_{g}(R)$

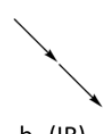

$b_{u}(I R)$

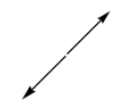

$a_{g}(R)$

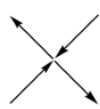

$a_{1 g}(R)$
Figure 8. Schematic view of active vibration modes for cyano groups of TCNB in Infrared (IR) and Raman (R) spectroscopies, in D2h and C2h space groups. The mirror planes are shown for the two symmetries as well as the $\mathrm{H}$-bonds for the $\mathrm{C}_{2 \mathrm{~h}}$ symmetry.

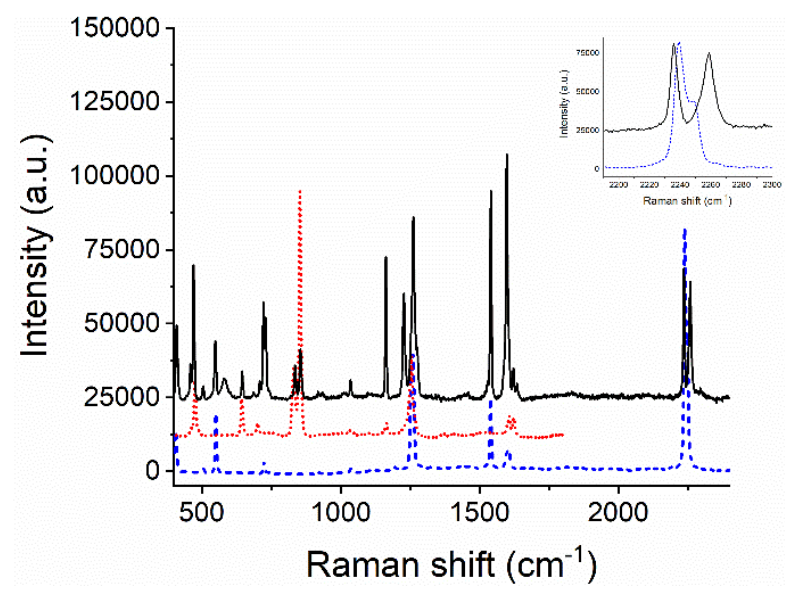

Figure 9. Raman spectra of TCNB (blue dashed line), $\mathrm{H}_{2} \mathrm{Q}$ (red dotted line) and TCNB$\mathrm{H}_{2} \mathrm{Q}$ CTC (black line). Inset: zoom of the nitrile vibration region.

\section{UV-visible spectroscopy}

Whereas most of the starting materials are white compounds, UV-vis spectra of CTCs exhibit a strong and broad absorption band between 400 and $600 \mathrm{~nm}$, depending on the nature of the hydroquinone. They were obtained starting from crystals diluted in $\mathrm{KBr}$, as for IR spectra, or from co-grinded powders diluted in $\mathrm{KBr}$. Indeed, a solid state reactivity similar to that encountered with quinone-hydroquinone pairs occurs ${ }^{22}$. Thus, co-grinding of equimolar mixtures of TCNB and hydroquinone derivatives led to coloured powders, which indicate the formation of CTCs. The absorption band position determined on $\mathrm{KBr}$ pellets, in the visible region, highly depends on the donating character of the hydroquinone (Fig. 10, Table 3). With the aim to tentatively classify the obtained CTCs, and because the electronic density on the hydroquinones is somehow related to the reduction potential of corresponding quinones, we propose hereafter a correlation between the charge transfer energy of TCNB- $\mathrm{H}_{2} \mathrm{Q}$ CTCs and this redox potential.
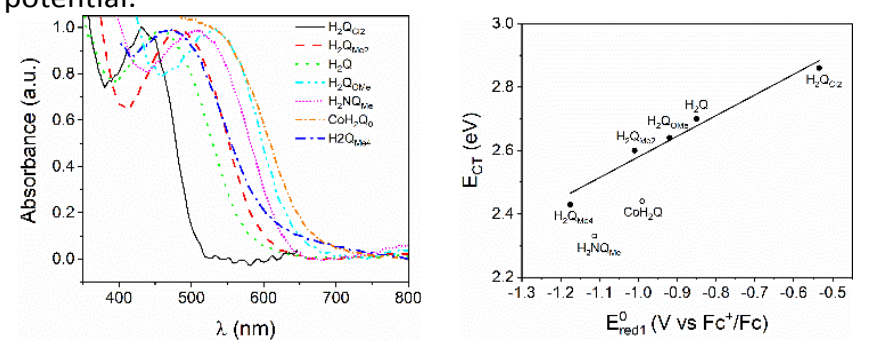

On the basis of published electrochemical data, we established a classification ranging from dichloroquinone to tetramethylquinone (Table 3). 
Figure 10. (left) Visible absorption spectra of charge transfer complexes obtained by cogrinding of TCNB with a series of hydroquinones in $\mathrm{KBr}$ pellets (absorption-diffusion of a virgin $\mathrm{KBr}$ pellet has been subtracted) ; (right) correlation between the $\mathrm{CT}$ transition energies, $E_{C T}$, and the redox potentials of the quinone derivatives, $\mathrm{E}_{\text {red1 }}^{\circ}\left(\mathrm{BQ} / \mathrm{BQ}^{-}\right)$, vs
$\mathrm{Fc}^{+} / \mathrm{Fc}$ (right). The straight line corresponds to the linear fit calculated with all the experimental values except that of $\mathrm{H}_{2} \mathrm{NQ}_{\mathrm{Me}}$ and $\mathrm{CoH}_{2} \mathrm{Q}_{0}$ (white circles).

Table 3. Optical characteristics of charge transfer complexes obtained by co-grinding of TCNB with a series of hydroquinones and redox potentials of the quinone derivatives, $\mathrm{E}^{\circ}{ }_{\mathrm{red} 1}(\mathrm{BQ} / \mathrm{BQ})^{23}$, vs Fc+/Fc.

\begin{tabular}{|c|c|c|c|c|c|c|c|}
\hline & $\mathrm{H}_{2} \mathrm{Q}_{\mathrm{Cl} 2}$ & $\mathrm{H}_{2} \mathrm{Q}$ & $\mathrm{H}_{2} \mathrm{Q}_{\mathrm{OMe}}$ & $\mathrm{H}_{2} \mathrm{Q}_{\mathrm{Me} 2}$ & $\mathrm{CoH}_{2} \mathrm{Q}_{0}$ & $\mathrm{H}_{2} \mathrm{Q}_{\mathrm{Me} 4}$ & $\mathrm{H}_{2} \mathrm{NQ}_{\mathrm{Me}}$ \\
\hline$\lambda \max (\mathrm{nm})$ & 433 & 460 & 470 & 476 & 509 & $510(\mathrm{sh})^{\mathrm{c}}$ & 533 \\
\hline color & yellow & orange & $\begin{array}{c}\text { orange } \\
\text { rust }\end{array}$ & $\begin{array}{c}\text { orange } \\
\text { red }\end{array}$ & $\begin{array}{c}\text { red } \\
\text { beetroot }\end{array}$ & brown & lilas \\
\hline RGB code ${ }^{a}$ & $220-210-10$ & $190-50-20$ & $190-15-5$ & $125-20-5$ & $50-15-20$ & $60-15-25$ & $45-20-10$ \\
\hline $\mathrm{E}_{\mathrm{CT}}(\mathrm{eV})$ & 2.86 & 2.70 & 2.64 & 2.60 & 2.44 & 2.43 & 2.33 \\
\hline$E_{\text {red }}^{\circ}$ & -0.535 & -0.85 & $-0.92^{d}$ & -1.01 & -0.99 & -1.175 & -1.11 \\
\hline
\end{tabular}

${ }^{a}$ measured by a numeric colorimeter, after scanning of the CTC series as pure powders kept between two glass slides; ${ }^{b}$ redox potentials $E^{\circ}\left(Q / Q^{-1}\right) ;{ }^{c}$ a partial reoxidation into $B Q_{\text {Me } 4}$ occurs, and the $\mathrm{CT}$ absorption band appears as a shoulder; ${ }^{\mathrm{d}}$ deduced from standard midpoint potentials determined in aqueous solution, using BQ as a reference (0.699 $\mathrm{V}$ vs $\mathrm{NHE}$ ).

The comparison between the different examples appeared rather difficult since the electrochemical values are related to different phenomena and depend on the experimental conditions (solvent, electrolyte, reference, and so on ...). We used the first reduction potentials, $\mathrm{E}_{\text {red1 }}^{\circ}\left(\mathrm{BQ}^{\mathrm{B}} \mathrm{BQ}\right)$, determined in an organic medium under the same conditions for all the quinones, taking $\mathrm{Fc}^{+} / \mathrm{Fc}$ as a reference ${ }^{23}$, except for $\mathrm{BQ}_{\mathrm{OMe}}$ studied in benzene instead of acetonitrile ${ }^{24}$. More than $0.8 \mathrm{~V}$ separate the redox potentials of the studied quinones. When quinhydrone - type CTCs are considered these potential values can be used to know if some quinone $B Q_{i}$ can react with some hydroquinone $\mathrm{H}_{2} \mathrm{Q}_{\mathrm{j}}$ to yield $\mathrm{H}_{2} \mathrm{Q}_{\mathrm{i}}$ and $B \mathrm{Q}_{\mathrm{j}}$, in a cross reaction. This can occur as soon as the reduction potential of $\mathrm{BQ}_{\mathrm{i}}$ is more positive than that of $\mathrm{BQ}_{\mathrm{j}}$. This is the reason why $\mathrm{BQ}$ reacts with $\mathrm{H}_{2} \mathrm{Q}_{\mathrm{OMe}}$ to give a CTC that involves $\mathrm{H}_{2} \mathrm{Q}$ and $\mathrm{BQ}_{\mathrm{OMe}}{ }^{3}$. On the contrary, duroquinone is supposed to form a CTC with all the hydroquinones. For the same reason, the 2,3-dichloro5,6-dicyano-1,4-benzoquinone, known as a true oxidizing agent, will not be able to form any CTC with any hydroquinone derivative. However, in the present study, such redox reactions are not a problem, because we prepared CTCs with TCNB, a non-redox active acceptor species.

A correlation appears between the $C T$ transition energies, $E_{C T}$ (in eV), calculated from the maximum wavelength in the electronic absorption spectra, and the redox potentials of the quinone derivatives, $\mathrm{E}_{\text {red1 }}^{\circ}\left(\mathrm{BQ} / \mathrm{BQ}^{-}\right)$, except for the coenzyme $\mathrm{CoH}_{2} \mathrm{Q}_{0}$ and the naphthohydroquinone $\mathrm{H}_{2} \mathrm{NQ}_{\mathrm{Me}}$. In the latter case, the presence of the naphthalene unit is supposed to facilitate the $\pi-\pi$ interaction between the acceptor and donor partners. However, $\mathrm{H}_{2} \mathrm{NQ}_{\mathrm{Me}}$ leads to a CTC band of lower energy, compared to this obtained with $\mathrm{H}_{2} \mathrm{Qs}$ with the same reduction potential. It probably results from the fact that only half of the molecule participates to the CT interactions. The straight line corresponds to the linear fit calculated with all the experimental values except that of $\mathrm{CoH}_{2} \mathrm{Q}_{0}$ and $\mathrm{H}_{2} \mathrm{NQ}_{\mathrm{Me}}$. Such a relation between the energy of charge transfer complexes and the redox potential values was already reported for a series of quinones with hexamethylbenzene ${ }^{25}$.

In addition, the RGB code as depicted by a numeric colorimeter (Apple Computer Inc., 3.4.1), after scanning of the CTCs series as pure powders kept between two glass slides, provided another signature of the optical characteristics of the CTCs (Table 3).

Even though such solvent-free techniques are more often used to get metal complexes rather than organic materials, the present study offers additional mechanochemical methods. Thus, the present processing techniques could be applied to other types of CTCs, such as semiconducting materials, which require the deposition on electrode surfaces ${ }^{26}$. They are also important if we keep in mind that the properties of materials can depend on their preparation conditions, as very recently reported for pharmaceutical solid forms with better pharmacokinetic parameters, prepared by other mechanochemical methods ${ }^{27,28}$.

\section{Experimental}

The 2,6-dimethoxy-1,4-dihydroquinone, $\mathrm{H}_{2} \mathrm{Q}_{\mathrm{OMe2}}$, was synthesized from $\mathrm{BQ}_{\mathrm{OMe2}}$, by reduction with $\mathrm{NaBH}_{4}$ in ethyl alcohol, at room temperature, under argon, adapted from a method previously reported for other hydroquinones ${ }^{29}$. After $2 \mathrm{~h}, \mathrm{HCl} 0.2 \mathrm{M}$ was

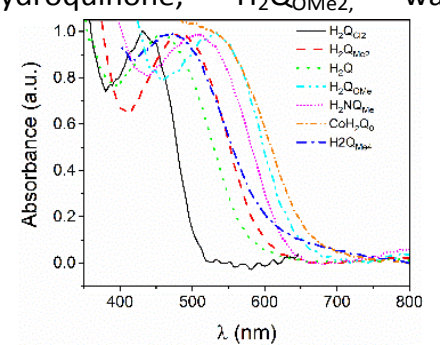
added, the product extracted by $\mathrm{CH}_{2} \mathrm{Cl}_{2}$ and dried on $\mathrm{MgSO}_{4}$. 
FT-IR spectra were recorded between 4000 and $400 \mathrm{~cm}^{-1}$ using a PerkinElmer Spectrum 100 FT-IR spectrometer. UV-visible electronic absorption spectra were recorded on a Shimadzu 2001 UV spectrophotometer. Raman spectroscopy was conducted employing a Renishaw inVia Raman microscope with a $633 \mathrm{~nm}$ laser.

X-ray structure determination and PXRD analysis: All experimental data procedure and refinement are detailed in Supplementary Information.

TGA was carried out on a Discovery TGA from TA Instrument,

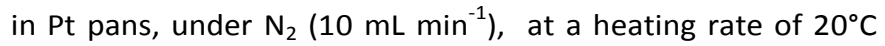
$\min ^{-1}$.

\section{Conclusions}

CTCs were obtained in the form of crystals between the TCNB and a series of $\mathrm{H}_{2} \mathrm{Qs}$. A simple co-grinding of the TCNB with its electron donating partner makes it possible to form the CTCs, as shown by the coloration of the obtained powders. The charge transfer band lays between 430 and $530 \mathrm{~nm}$. The energy of this CT band is correlated with the reduction potential of the corresponding BQs. The donor effect of the substituents on the hydroquinone causes a decrease in the energy of CT. Co-sublimation in a confined environment is an attractive alternative to conventional co-evaporation. It has the advantage of being much simpler to process and of obtaining crystals much more quickly. It even made it possible to get single crystals of sufficiently large size and of good quality to achieve the crystal structure in the case of the TCNB$\mathrm{H}_{2} \mathrm{Q}$ complex. Furthermore, we also report here the structure of the TCNB- $\mathrm{H}_{2} \mathrm{Q}_{\mathrm{OMe}}$ and TCNB- $\mathrm{H}_{2} \mathrm{Q}_{\mathrm{OMe} 2}$ complexes. In TCNB$\mathrm{H}_{2} \mathrm{Q}$, acceptors and donors alternate in columns connected to each other by $\mathrm{H}$-bonds, while in TCNB- $\mathrm{H}_{2} \mathrm{Q}_{\mathrm{OMe}}$ and in TCNB$\mathrm{H}_{2} \mathrm{Q}_{\mathrm{OMe} 2}$, the stoichiometry 1 to 2 is observed and molecules arrange in TCNB- $\left(\mathrm{H}_{2} \mathrm{Q}_{\mathrm{OMe}}\right)_{2}$ triads. In TCNB- $\left(\mathrm{H}_{2} \mathrm{Q}_{\mathrm{OMe}}\right)_{2}$, molecules are highly, with rather weak $\pi-\pi$ interactions, compared to what occurs in TCNB- $\left(\mathrm{H}_{2} \mathrm{Q}_{\mathrm{OM} 2}\right)_{2}$. Raman spectroscopy, and to a lesser extent infrared spectroscopy, are methods of choice to highlight the formation of a CTC. Aside from $\mathrm{H}_{2} \mathrm{Q}_{\mathrm{F} 4}$ - based CTC, the spectra are not the simple superposition of the spectra of the two constituents. This is particularly true for the $\mathrm{C}-\mathrm{N}$ vibration of the nitrile function, which proves to be a good probe for demonstrating the formation of such CTCs.

\section{Conflicts of interest}

There are no conflicts to declare.

\section{Acknowledgements}

Financial support from the European Union (FEDER) and the Conseil Régional de Bourgogne through the CDEA program is gratefully acknowledged. We also acknowledge the Conseil Régional de Bourgogne through the CPER program. The authors thank the "Plateforme d'Analyses Chimiques et de Synthèse Moléculaire de l'Universite de Bourgogne" (PACSMUB) for technical support in the Raman analyses. The Conseil Régional de Bourgogne Franche-Comté is gratefully acknowledged for financial support of this platform. The authors thank Elodie Grail, a Master CAC student, for studying one of the CTC complexes.

\section{References}

1 J.-M. Lehn, Chem. Soc. Rev., 2007, 36, 151-160.

2 C. J. Bruns and J. F. Stoddart, The Nature of the Mechanical Bond, John Wiley \& Sons, Hoboken, NJ, USA, 2016.

3 M. Bouvet, B. Malézieux and P. Herson, Chem. Commun., 2006, 1751-1753.

4 M. Guergova-Kuras, B. Boudreaux, A. Joliot, P. Joliot and K. Redding, PNAS, 2001, 98, 4437-4442.

5 C. Liehn, $M$. Bouvet and R. Meunier-Prest, ChemElectroChem, 2014, 1, 2116-2123.

6 S. K. Park, J. H. Kim, T. Ohto, R. Yamada, A. O. F. Jones, D. R. Whang, I. Cho, S. Oh, S. H. Hong, J. E. Kwon, J. H. Kim, Y. Olivier, R. Fischer, R. Resel, J. Gierschner, H. Tada and S. Y. Park, Adv. Mater., 2017, 29, 1701346.

7 Y. L. Lei, Y. Jin, D. Y. Zhou, W. Gu, X. B. Shi, L. S. Liao and S. T. Lee, Adv. Mater., 2012, 24, 5345-5351.

8 L. Sun, W. Zhu, W. Wang, F. Yang, C. Zhang, S. Wang, X. Zhang, R. Li, H. Dong and W. Hu, Angew. Chem. Int. Ed. Engl., 2017, 56, 7831-7835.

9 P. Hu, S. Wang, A. Chaturvedi, F. Wei, X. Zhu, X. Zhang, R. $\mathrm{Li}, \mathrm{Y}$. Li, H. Jiang, Y. Long and C. Kloc, Cryst. Growth Des., 2018, 18, 1776-1785.

10 J. Jalkh, Y. R. Leroux, A. Vacher, D. Lorcy, P. Hapiot and C. Lagrost, J. Phys. Chem. C, 2016, 120, 28021-28030.

$11 \mathrm{H}$. Jiang, P. Hu, J. Ye, K. K. Zhang, Y. Long, W. Hu and C. Kloc, J. Mater. Chem. C, 2018, 6, 1884-1902.

12 Y. Imai, N. Tajima, T. Sato and R. Kuroda, Org. Lett., 2006, 8, 2941-2944.

13 Y. Imai, T. Kinuta, K. Kamon, N. Tajima, T. Sato, R. Kuroda and Y. Matsubara, Cryst. Growth Des., 2009, 9, 2393-2397.

14 M. Riskin, R. Tel-Vered, T. Bourenko, E. Granot and I. Willner, J. Am. Chem. Soc., 2008, 130, 9726-9733.

15 P. Hu, K. Du, F. Wei, H. Jiang and C. Kloc, Cryst. Growth Des., 2016, 16, 3019-3027.

$16 \mathrm{M}$. Bouvet, B. Malézieux, P. Herson and F. Villain, Helv. Chim. Acta, 2009, 92, 453-461.

17 X. Ye, Y. Liu, Q. Guo, Q. Han, C. Ge, S. Cui, L. Zhang and X. Tao, Nat. Commun., 2019, 10, 1-9.

18 H. Bock, W. Seitz, M. Sievert, M. Kleine and J. W. Bats, Eur. J. Org. Chem., 1996, 1996, 1929-1940.

19 M. Svärd, D. Ahuja and Å. C. Rasmuson, Cryst. Growth Des., 2020, 20, 4243-4251.

20 D. Ahuja, M. Svärd, M. Lusi and A.. C. Rasmuson, CrystEngComm, 2020, 22, 3463-3473. 
21 J. Umemura, L. V. Haley, D. G. Cameron, W. F. Murphy, C. F. Ingold and D. F. Williams, Spectrochim. Acta A, 1981, 37, 835845.

22 M. Bouvet, B. Malézieux, P. Herson and F. Villain, CrystEngComm, 2007, 9, 270-272.

23 Carlos Frontana, Álvaro Vázquez-Mayagoitia, Jorge Garza, A. Rubicelia Vargas and I. González, J. Phys. Chem. A, 2006, 110, 9411-9419.

24 D. E. Kvalnes, J. Am. Chem. Soc., 1934, 56, 670-672.

25 M. E. Peover, ed. A. J. Bard, Marcel Dekker, New York, 1967, vol. 2.

26 A. Mandal, A. Choudhury, R. Kumar, P. K. Iyer and P. Mal, CrystEngComm, 2020, 22, 720-727.

27 J. Haneef and R. Chadha, CrystEngComm, 2020, 22, 25072516.

28 K. K. Sarmah, N. Nath, D. R. Rao and R. Thakuria, CrystEngComm, 2020, 22, 1120-1130.

29 S. Meddeb-Limem, B. Malézieux, P. Herson, S. BesbesHentati, H. Said, J.-C. Blais and M. Bouvet, J. Phys. Org. Chem. 2005, 18, 1176-1182. 